\section{Being bisexual in contemporary Italy: between stigma and desire of visibility}

Being bisexual in contemporary Italy

\author{
Salvatore Monaco
}

Faculty of Education, Free University of Bozen-Bolzano, Bolzano, Italy

\begin{abstract}
Purpose - The Italian sociological scientific community has shown a limited interest in issues related to bisexuality. The purpose of this paper is to fill the knowledge gap on the subject, showing data of an empirical research conducted online on the Italian bisexual community.

Design/methodology/approach - The article is based on a mixed methods online survey on Italian bisexual people, which included 218 interviews. The questionnaire was made up of closed and open-ended questions, to investigate their behaviours, habits and lifestyles.

Findings - Social pressure and lack of understanding by others sometimes make difficult for bisexual people to show themselves openly for what they are, especially in some contexts, such as the word of work. From a sociological point of view, one can argue that one of the tools when bisexual people face the stigma related to bisexuality is to control, often in an obsessive way, the information they provide about themselves, carefully evaluating the contexts in which they can free themselves and the time when they must expose themselves in line with the expectations of the heteronormative society.

Research limitations/implications - The non-probabilistic sample limits the external validity of the findings. There are also critical elements that characterise social research when transposed online: first, the profiles of the respondents not always are verifiable; second, the digital divide excludes some groups that cannot access the web or involves an over-representation of those who are more familiar with technologies.

Originality/value - The work presented is the first Italian sociological study aimed at deepening the "invisible B" phenomenon of the LGBT acronym in a systematic way. Nowadays bisexuality remains underresearched in social sciences and overall in sociology. Putting "bisexuality" at the centre of the sociological attention appears important to provide serious and scientifically valid data and information useful both to develop the knowledge on this identity category and to contain forms of discrimination and prejudice.
\end{abstract}

Keywords Bisexuality, Italy, Stigma, Gender studies

Paper type Research paper

\section{Introduction}

Although several studies have demonstrated that sexual orientation is something fluid, changeable throughout life (see, e.g. Crooks and Baur, 2016; Diamond, 2009; Dettore and Lambiase, 2011; Savin-Williams et al., 2012; Weiten et al., 2016), in the collective imagination, the idea that there is a strong polarisation of sexual identities that sees homosexual people on one hand and heterosexual ones on the other still exists (see, e.g. Jagose, 1996; McPhail, 2004). This conviction delegitimises all the identities that are placed in the middle, away from this dichotomy.

(c) Salvatore Monaco. Published by Emerald Publishing Limited. This article is published under the Creative Commons Attribution (CC BY 4.0) licence. Anyone may reproduce, distribute, translate and create derivative works of this article (for both commercial and non-commercial purposes), subject to full attribution to the original publication and authors. The full terms of this licence may be seen at http:// creativecommons.org/licences/by/4.0/legalcode

The author would like to thank Prof. Fabio Corbisiero (University of Naples Federico II) and Prof. Urban Nothdurfter (Free University of Bozen) for their useful comments and the anonymous reviewers for their insightful suggestions and careful reading of the manuscript. The author also has to thank Guido Guarino, Marco Petrarca, Steven Ding and the Osservatorio LGBT's staff of University of Naples Federico II. The University Research Centre is coordinated by Prof. Fabio Corbisiero.

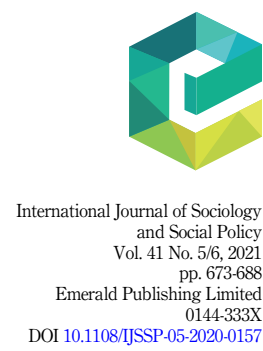


IJSSP

$41,5 / 6$

674

In this scenario, we can find bisexual people who are sexually and/or romantically attracted to more than one sex and/or gender, not necessarily in the same way, with the same intensity and at the same time (see, e.g. Eisner, 2013; Flanders, 2017; Weinberg et al., 1995). Bisexuality is sometimes a controversial concept. It also depends on the fact that sexual attraction, behaviour and identity may be incongruent (D'Lane et al., 2015); in other words, sexual attraction or behaviour may not necessarily be consistent with identity (Butler, 1990). Some individuals identify themselves as bisexual without having had any sexual experience. Other persons can have in their lives both homosexual and heterosexual experiences but do not consider themselves as bisexual. At same time, self-identified gay or lesbian people may occasionally sexually or romantically interact with members of the opposite gender but do not identify themselves as bisexual (Eisner, 2013; Flanders, 2017).

In line with a recent definition, "bisexuality refers to sexual attraction occurring regardless of sexed body type. Sexologist Alfred Kinsey asserted that all humans are functionally bisexual and developed what became known as the Kinsey scale, which plotted all people somewhere between 0 (exclusive heterosexuality) and 6 (exclusive homosexuality). By default, anyone plotted from 1 to 5 was a varying degree of bisexual” (Davies, 2018).

In the current social context, bisexuality receives limited public focus. The bisexual people's social invisibility is also translated into political invisibility: their requests, needs and claims remain ignored or are put together with those of people who declare themselves homosexual or heterosexual exclusively, depending on the circumstances.

For this reason, the American bisexual movement, originated from the United States in the 1990s, underlines the importance of considering the requests of bisexual people from a social, cultural and political point of view. This bisexual movement has also helped set up the day of bisexual pride and visibility (September 23rd) and encouraged some interesting initiatives. In 2013, for example, the White House celebrated the bisexual pride day by inviting the leaders of the major American bisexual organisations to a meeting in which they discussed the problems of bisexual people. In addition, since 2014, some American organisations have struggled to ensure that the National Health System organised annual initiatives for focussing on bisexual people's health and well-being awareness.

As for social sciences, in America, some sociological reflections on this issue were realised. In particular, some recent studies have focussed on the labour market and on the relationship between (bi)sexual orientation and earnings (see, e.g. Klawitter, 2014; Mize, 2016), on family experiences (see, e.g. Scherrer et al., 2015) and on discrimination and prejudice experienced in everyday life (see, e.g. Friedman et al., 2014; Herek and McLemore, 2013; Israel and Mohr, 2004; Yost and Genea, 2012).

On a global scale, America almost represents an exception, since in other contexts bisexual communities are still struggling to make them heard. As Rust suggests (2000), in the social sciences, academic audience "barely acknowledged its existence" (p. 129). This is especially true in Italy, which is the context of the current study. The lack of Italian studies on bisexual people makes it clear that their requests and claims, already excluded from the political discourse, do not even find space in the sociological literature on sexual minorities.

Starting from these assumptions, this paper presents a sociological work on the Italian bisexual population with the aim of filling the knowledge gap on this subject.

The object of the research is to study bisexuality as a social experience, to understand what being bisexual means in the contemporary and to individuate if there are areas where (bi)sexual orientation is able to affect people's lives. In Italian social research, bisexual people are still very invisible. The few realised researches are concentrated on very specific aspects. This study aims to better outline the profile of bisexual people, highlighting their experiences and the specific challenges that they face every day. A specific study focussed on bisexual people living in Italy is important to make their reality more visible, to give voice to them and to contrast their marginalisation even within the LGBT community. 
More specifically, this sociological study aims at identifying the respondents' sociodemographic characteristics (gender, age, religious beliefs and political orientation) and at exploring their behaviours, habits and lifestyles in some of the main areas of social life: mobility, intimate relationships and work. From this critical perspective, the research not only contributes to the body of knowledge, but it is also useful for identifying some implications for practice and the society.

In first part of this paper, the social, political and historical background on LGBT rights in Italy is briefly demonstrated, followed by a review of the main sociological research about bisexual people living in Italy. After describing the research methodology, in the paper the main results of the survey are presented. The paper concludes with some useful reflections not only to guide sociological research on this issue but also to support the political class to improve the conditions of bisexual people currently living in Italy.

\section{Bisexuality as issue in Italy}

Italy is one of the most politically backward countries in Europe in terms of the protection of LGBT people's rights. According to the Rainbow Index of ILGA Europe, the European section of the International Lesbian and Gay Association, Italy has fallen down from the 32nd position to the 34th (among a total of 49 countries) in one year, shifting from 27 to $22 \%$, for what concerns the respect of the rights of LGBT people (ILGA, 2019). The rights of bisexual and homosexual people in Italy have significantly changed over the past few years, although these people still face several legal hurdles. In Italy, the sexual orientation of a citizen still does not remain under protection as there has not been any law established against the discrimination of sexual orientation. Affective and sexual relations between people of the same sex have been made legal since 1890 and a civil partnership law was approved in May 2016. However, the law does not grant same-sex couples the right to adopt. From a social point of view, a recent survey conducted at national level by the European Union Agency for Fundamental Rights (FRA, 2020) revealed that Italy (with including Luxembourg) is the European country with the highest percentage of people who felt discriminated in one of the areas of life during 2019 (across the $\mathrm{EU}$, on average $11 \%$ were reported. In Italy, the rate is $19 \%$ ). In line with other national statistical surveys (ISTAT, 2015), the European report highlighted that in Italian society, phenomena of homophobia and biphobia are still too widespread.

Despite this frame, the Italian sociological scientific community has shown less interest in issues related specifically to bisexuality. Thus, the bisexual condition has been commonly studied in the field of psychology (see, e.g. Petrocchi et al., 2020; Pistella et al., 2016; Scandurra et al., 2020; Verrastro et al., 2016) and anthropology (see, e.g. Castro and Carnassale, 2019) but the same cannot be said for sociology. In Italy, very often sociological studies and researches have generally spoken about the homosexual community or LGBT population, focussing mainly on gay males, over-generalising the results also to other under-represented categories of sexual minorities (Ruspini, 2013). This is a global critical practice (Mize, 2015). Although in recent years social sciences have shown an increasing interest in sexual orientation as a lens for reading social change (Hunt et al., 2014; Worthen, 2013), bisexual individuals are not duly taken into consideration as a separate group. It is very common that sociological surveys exclusively investigate homosexual men, leaving out lesbian women and, even more often, bisexual people, extending the results to the entire LGBT population. This approach offers a standardised and simplistic view of sexual minorities, omitting the specificities of each identity group (Herek, 2002; Corbisiero, 2013).

Among the largest and most complete researches on the LGBT population in Italy, there is Omosessuali Moderni (Barbagli and Colombo, 2001), a study that, even if offers some reflections on bisexuality, incorporates it into the more general homosexual question.

An Italian study specifically dedicated to bisexual people was carried out in 2007, with a specific focus on the labour market (Breveglieri, 2007). Through a series of in-depth 
IJSSP

$41,5 / 6$

676 interviews, this sociological research claims that bisexual people have greater difficulty finding work and earn less compared to their colleagues. Regarding the world of work, other interesting results were collected in the survey Io sono lavoro, realised by Arcigay in 2011. The research studied the occupation of a sample of LGBT subjects, categorising the results on the basis of gender identities and sexual orientations. According to this research, bisexual males are the subjects who, more than any other LGBT community members, suffer the most from discriminations (Arcigay, 2011).

Another thought-provoking Italian research that also dedicated a focus on bisexual people was Modidi (Pietrantoni et al., 2005). This empirical study was realised by Arcigay and Arcilesbica to focus on LGBT people's health. A remarkable result that emerged about bisexual people is that they come out less frequently. This behaviour is particularly true for women, who do not declare their sexual orientation even to their gynaecologist, unlike lesbian women, who, instead, reveal their sexual orientation more easily to professionals.

In 2018, through an intersectional perspective, referring to the Greimas semiotic square, Gusmano read the process of coming out experienced by three bisexual people about their polyamorous relationships (Gusmano, 2018). Polyamory is a philosophical position which opposes to the postulate of social monogamy as a necessary convention. In other words, it admits the possibility of a person having multiple intimate relationships simultaneously, as long as there is the informed consent of all partners involved (Veaux and Rickert, 2014).

\section{Materials and methods}

During the closing months of 2018, the "Osservatorio LGBT" of the University of Naples "Federico II" conducted a questionnaire research, consisting of both close-ended and open-ended questions, to investigate behaviours, habits and lifestyles of LGBT population in Italy.

The survey tool was built by a group of experts in gender studies from various disciplines, including sociology, psychology, economics, jurisprudence and statistics. For the validation of the questionnaire, three focus groups with LGBT associations were organised.

In its final version, the complete questionnaire was made up of different sections, aiming at investigating the profile of the interviewees (gender, age, place of residence), habits of consumption and behaviours (media and cultural consumption, emotional and family relationships, tourist choices, etc.), opinions and attitudes about their living condition and social needs.

The questionnaire was computerised and administered through Qualtrics. The introduction page specified that the eligible respondent must be 18 years old or above. The first page of the questionnaire stated researchers' email addresses and affiliations, as well as context of the survey; specifically, participants were informed about the aims of the research, completion times, benefits and risks, as well as about the anonymity of the responses and the right to stop the survey at any point and for any reasons.

During 2019, 1600 copies of questionnaires from Italian LGBT people were collected.

The use of the CAWI technique for this survey resulted from a series of methodological considerations.

Firstly, analysing a population like the LGBT community that is stigmatised, fragmented and uncensored has consequences for the sampling plan (Goffman, 1963). LGBT people are part of the so-called hidden populations, communities of people who tend not to openly manifest their identity since they are discriminated for one or more of their characteristics or behaviours (Baumle et al., 2009; Matthews and Cramer, 2008). For LGBT people, the fear of being victims of abuse and the difficulties that can arise in expressing openly their sexuality are social stressors that keep subjects from declaring their sexual orientation, and they choose to hide it. A face-to-face interview would have produced less satisfactory results. 
Starting from these considerations, researchers thought that spreading the survey online would help extend the number of respondents, as contemporary society is characterised by the affirmation of the Internet as a dominant means of communication on the media scene, by the proliferation of mobile devices and extensive technological literacy (see, e.g. Bauman, 2011; Daniels and Gregory, 2016; Dolata and Schrape, 2018; Surratt, 2001). It is also widely accepted that online surveys allow the construction of larger and heterogeneous samples than traditional ones (Hine, 2005). It is safe to say that the non-probabilistic sample limits for its nature the external validity of our findings. To contain the effects of such limit, it would be more advisable to spread the survey on social networks and not just on the websites of LGBT associations. Thus, the link of the questionnaire was also found on sites and social pages of companies other than the LGBT associations, such as clubs, bars, discos and pages dedicated to young people and social life in general.

These first two aspects are linked to another one: people belonging to sexual minorities often tend to provide answers that in their minds are most acceptable to the questions (Edwards, 1957). Conducting online interviews somewhat eases the bias of "social desirability" (Krumpal, 2013; Monaco, 2019; Snee et al., 2016) because people can answer even extremely sensitive questions without the presence of an interviewer, whom they tell untrue things in order to appear as someone they would like to be. Also for this reason, the most part of surveys uses almost exclusively self-administered questionnaires, such as the "Gay Men's Sex Survey". The realisation of the online survey enabled people to answer to the questionnaires anonymously and voluntarily, without the fear of having to expose themselves thanks to the fact that they are behind a screen.

However, it is appropriate to highlight some critical elements that still characterise social research when transposed online. The first problem related to the collection of online data is that the profiles of the respondents are not always verifiable; yet, since the adherence to this type of survey is voluntary, it is very unlikely that people will dedicate $20 \mathrm{~min}$, on average, to entering false information.

Another limitation of online researches is the digital divide, which excludes some groups that cannot access the web or involves an over-representation of those who are more familiar with technologies, the youngest generation of the population.

In the following paragraphs, the results related exclusively to people who have defined themselves as bisexual will be presented. The non-probabilistic sample of bisexual subjects is made up of 218 people.

\section{Results}

\subsection{Profiles, gender identities and beliefs}

Over 1600 LGBT participants took part in the survey. Among them, 218 defined themselves as bisexual, ranging from 18 to 63 years old (26 years old on average). As regards gender identities, the majority self-identified as cisgender (141 cisgender women vs 50 cisgender men), while 8 self-identified as transgender men, 4 as transgender women and 15 as nonbinary. As a result, the sample involves people whose gender identity matches the sex that they were assigned at birth, individuals that have a gender identity or gender expression that differs from their sex assigned at birth find a mismatch between the psychological gender and the biological one and people who do not fit into the gender binary, that is, those who do not consider their identities either exclusively masculine or exclusively feminine.

The wide spectrum of answers collected allows to argue that bisexuality is an orientation that involves a multitude of genders and identities. Thus, the attempt to firmly narrow down the boundary of sexual orientation to only one or some gender identities without bisexual is undoubtedly untenable. This wrong tendency may devalue or remove the specific features of the individual categories that make up the bisexual population. In particular, it is important to 
IJSSP

$41,5 / 6$

678

highlight the presence of transgender people in the sample. Simplistically, people sometimes think that the individuals who decide to transition from one gender to another must fall into a stereotype, so transgender women must orient their physical, romantic and/or emotional attraction exclusively towards men, as well as a person who is assigned female at birth and transitions to male must direct his sexual or romantic interest exclusively towards women. There is not an assumption more indefensible than this one: gender identity and sexual orientation are two distinct dimensions of sexual identities. Like cisgender individuals, transgender people may be straight, lesbian, gay, bisexual or asexual. A 2015 survey of roughly 3,000 American transgender women has shown that transgender people frequently remain as attached to loved ones after transition as they were before transition (James et al., 2016).

The greater presence of women who defined themselves bisexual in the sample could be explained by the trend of men to base their identity on the awareness of a stable and strongly polarised sexual orientation between heterosexuality and homosexuality (Albury, 2015). Bisexual orientation is consequently refused, for encouragement of greater self-acceptance. Female sexuality and sexual orientation, on the other hand, seem more "fluid" and are often re-defined based on the social and cultural contexts and sentimental situations and relationships that women live with in their daily lives (see, e.g. Diamond, 2008; Peplau and Garnets, 2000).

As for religious beliefs, $46.7 \%$ declared themselves atheists and $20.3 \%$ agnostic. $23.1 \%$ of the respondents stated to be Catholic, although almost half of them said they were not churchgoers. The remaining $10 \%$ of respondents are said to follow other religions (such as Buddhism and Pantheism).

Almost half of the sample ( $43.4 \%$ ) has a predominantly leftist political orientation. The other half is divided between voters of right-wing and centre-right parties $(27.8 \%)$ and sympathisers of new independent political movements (16.2\%), as Five Star Movement (Movimento Cinque Stelle). The remaining 12.6\% of respondents claimed to be apolitical. This data is explained by the greater open-mindedness exercised by the Italian left-wing political parties towards the LGBT issues compared to the more conservative right-wing ones. As Huneke suggests (2019), in the Western countries, the LGBT electorate clearly supports democratic parties, even if there is a percentage of homosexual and bisexual people that vote for conservative or far-right parties. In 2018, for example, during the mid-term elections, $82 \%$ of the US LGBT electorate voted for the Democratic Party.

\subsection{Territorial mobility, tourist choices and coming out}

From a territorial point of view, the interviewees are distributed throughout the country (the region with the highest percentage of respondents is Lombardy, followed by Emilia Romagna and Campania). Almost half of the people interviewed declared to live in medium-sized urban centres (with a population between 20,000 and 250,000). The remaining half is divided between $30 \%$ of people living in large conurbations (with over 250,000 inhabitants) and $21.4 \%$ of people living in small urban centres (with less than 20,000 inhabitants). $43 \%$ of the people who responded to the survey said to have moved out of their living cities in their lifetime.

It is not surprising that, in most cases, the migration from smaller cities to larger urban centres has various reasons. About $73.2 \%$ of the respondents were identified to have transferred from one city to another because they wanted to pursue further study $(39.2 \%)$, to find more job opportunities (18.6\%) and for family reasons $(15.4 \%)$. The remaining $26.8 \%$ is divided between people who have moved in the hope of a better livelihood where there are greater services and infrastructure $(8.3 \%)$ and those who have instead chosen to change cities due to socio-cultural hostility towards their sexual orientation $(18.6 \%)$. As a result, almost 
two people out of ten among those who changed their city of residence answered that they did it also because of their bisexuality:

I decided to change city because my old school friends made fun of me.

(Cisgender woman, 20 years old, from Piverno to Rome)

I moved because the people who live in the city where I was born are too close-minded and have always made me feel out of place.

(Cisgender woman, 27 years old, from Catanzaro to Venice)

I decided to leave my city to live in a place where more rights are guaranteed to LGBT people.

(Cisgender woman, 36 years old, from Terni to Rome)

I do not want to live in my hometown because of the limited opportunities for personal and collective growth of the LGBT community and also because of the hostile social climate.

(Cisgender woman, 26 years old, from Benevento to Naples)

As suggested elsewhere, the research data confirm that in Italy, the big cities represent the place where people belonging to sexual minorities are supported and protected from discrimination and social exclusion, that they are forced to live in smaller and less inclusive contexts. In the Italian "rainbow cities" (Corbisiero and Monaco, 2017), which are mainly some of the largest regional capitals, local administrations plan and implement effective policies together with LGBT associations and other bodies of urban governance, with the aim of increasing integration and social cohesion. These initiatives appear fundamental in a country where there is still not an organic political design on the LGBT issues and the national legislation on non-discrimination is still scarce (Trappolin and Gusmeroli, 2020).

Difficult situations are also reported by people who have not changed their cities, but keep their condition as bisexual people secret. Especially for bisexual people, coming out is a gradual and never concluded process (see, e.g. Yoshino, 2006). The reasons for coming out can be political, but also practical, because when people have declared they are part of a minority, they no longer feel the stress of having to hide their identities and they can be themselves openly in all areas of life (see, e.g. Liang, 1997; Seidman, 2002). Some psychological studies have shown that people who hide part of their identity in society are more likely to experience severe conditions of stress and neurosis (see, e.g. D'Augelli, 2002). In addition, coming out generally leads to inner growth, especially in terms of self-confidence, as it takes people out from a zone of shame and exclusion (see, e.g. Rasmussen, 2004).

In line with other previous international studies (Balsam and Mohr, 2007), Italian bisexual people seem more likely to hide their bisexual orientation for fear of discrimination. In fact, about $30 \%$ of the interviewees confessed that they hide their bisexuality in their daily lives. In most cases, the strategy that they adopted is to speak only about the attraction towards people of the opposite gender, thus concealing an important part of their personality.

Among the main reasons that have been collected for an explanation of this type of behaviour, the most frequent one given by cisgender women is the fear of repercussions in their workplaces. Following is a selection of their answers:

I do not know if I am in a safe space to talk about my bisexuality with my colleagues.

(Cisgender woman, 27 years old, from Catania)

I am afraid of being dismissed from my workplace.

(Cisgender woman, 29 years old, from Bra)

\section{Being bisexual} in contemporary Italy 
IJSSP

$41,5 / 6$

680
Now I'm retired. I never came out at work because I did not want my boss to judge me on this subject.

(Cisgender woman, 62 years old, Milan)

My working environment leads me to think that there would be unpleasant consequences including the possibility of losing my position.

(Cisgender woman, 37 years old, Milan)

I had not openly declared my bisexuality at work because there could be prejudices that could compromise my job.

(Cisgender woman, 32 years old, Vercelli)

I work in a Catholic association of blatantly bigoted people. I am sure that if I came out I would be fired or at least condemned by them.

(Cisgender woman, 29 years old, Pordenone).

For what concerns cisgender men, the main fear is experiencing some form of social exclusion or prejudice. Some extracts of the interviews to support this belief are:

I am afraid that by coming out I will be subject to biphobia or marginalisation.

(Cisgender man, 21 years old, from Mussomeli)

My relatives do not know that I am having a relationship with a boy. They have seen me several times dating a girl. I do not know how they could react to my bisexuality.

(Cisgender man, 24 years old, from Naples)

I'm afraid of not being accepted.

(Cisgender man, 28 years old, from Pisa).

In addition, a separate discussion must be dedicated to transgender people. Although they are present in the study as a minimal percentage of the total sample, all of them said to have come out in their lives. This is probably explained by the fact that their transition from one gender to another has left physical changes that have somehow made implicitly visible their experiences and thus promoted them to reveal their actual sexual identity. So, it is safe to argue that gender transition may be the key to affirm not only their gender identity but also their sexual orientation. As Zimmam (2009) put "For these people, whose gender identity may very well align with how they are perceived by others, coming out does not mean revealing a gender identity, but rather a particular kind of gender history characterised by the movement from one gender category to another" (p. 54).

For many people, bisexuality also relates with tourism choices. $57.7 \%$ of respondents said that the choice of trip destination is "A lot" or "Enough" determined by the local social circumstances and by the local openness towards the LGBT community. In particular, there are people who carefully consider if the local socio-political environment is friendly to sexual minorities, $32.7 \%$ of respondents said that they would have wanted to visit Russia, but avoided going there. In the ranking of trip destinations avoided by bisexual people, follow Maghreb and the Middle East, but also some of the most conservative countries of America. An interesting data is represented by $20 \%$ of respondents who said to prefer going beyond Italy due to its lack of openness towards LGBT people.

\subsection{Prejudices and double stigma}

A further investigated aspect concerns romantic relationships. Respondents were asked if they had one or more partners and the kind of relationship they had. 
Among those who are emotionally or sexually related to someone, $80.7 \%$ said to have a monogamous relationship, $12.8 \%$ said they were in a relationship with more than two people and $6.5 \%$ declared to have more than two stable partners, staying in a so-called "polyamorous relationship". $32.7 \%$ did not have stable relationships.

This data lead to two consequent considerations: the first one is that polyamorous relationships are also spreading in Italy. In other words, a small group of respondents said they have stable non-monogamous relationships. The second assumption that the data allow to make is that the majority of Italian bisexual people, both men and women, prefer to have a stable relationship. The most part of declared relationships are long-lasting, even among the polyamorous ones.

This result contradicts one of the strongest prejudices on the subject, which associates bisexuality, especially the male one, with promiscuity and sexual restlessness (Brewster and Moradi, 2010; Feinstein and Dyar, 2017; Ron et al., 2014). Finally, another interesting data in order to understand bisexuality as a social experience is provided by the respondents' answers to the question "What are the needs of the Italian bisexual community?" The most clear result is the request for recognition and respect for their identity in the social context:

I think bisexuality is incorrectly viewed by heterosexual cisgender people. We cannot expect to be considered equal to them if they think we are what we are not. Revolutions must start from the bottom, we must go to the streets to talk to people and explain to them who we are, and that we are all different. They will never grant us the same rights if they do not understand that we are all equal in our diversities.

(Cisgender woman, 20 years old, from Cecina)

Among the most common stereotypes about bisexuality there is the association between this sexual orientation and promiscuity. It is a widespread belief not only among heterosexual people, but also among homosexual ones.

(Non-binary, 21 years old, from Foggia)

There is a need to make more visible and clear the LGBT community in general and bisexuality in particular. In my opinion there is much need to provide recent and well-collected data about this issue, in order to spread accurate and updated information to the general public. Being bisexual in Italy is sometimes very difficult. . . keeping our discomfort inside is painful. I do not wish it anyone. I hope that over time the society will be more inclusive towards us. We are all human.

(Cisgender woman, 21 years old, from Milan)

I believe that bisexual pride should be shown today. Let's not forget that bisexual people are subject to a double stigma.

(Cisgender man, 27 years old, from Pavia)

The extracts of the interviews reported earlier allow to claim that bisexual people often feel misunderstood and subject to prejudices and stereotypes, which are held not only by heterosexual people but also by homosexual ones. This double stigma condition often leads bisexual people to hide their identities in the LGBT community too. Even if they share the weight of heteronormativity with gay and lesbian people, bisexual persons are sometimes mistreated or misjudged by homosexual people. This makes the bisexual community a hidden minority within a sexual minority. Some scholars have described the bisexual people's condition by borrowing the concept of "intersectionality", which was introduced into the scientific literature by Crenshaw (1989), to describe the amplified condition of stress and social disadvantage that bisexual people experience and the possible overlapping of different social identities and the consequent multiple discriminations or dominations. As Eliason and Elia (2011) wrote, "We propose that sexuality studies scholars more seriously consider the 
IJSSP

$41,5 / 6$

682

issues of inter sectionality as an organising framework for addressing how bi-phobia and the resulting invisibility of bisexual identities and behaviours among highly diverse individuals can be conceptualized" (p. 417). Thus, when bisexual people are part of other minorities (such as ethnicity, geographical location, and religion, etc.), they are victims of multiple oppressions which, in addition to the former double discrimination, are capable of exacerbating their social marginalisation (see, e.g. Caldwell, 2010; Chun and Singh, 2010; Elia, 2010; King, 2013; Pallotta-Chiarolli, 2014; Rodriguez et al., 2013). From this critical angle, it appears clearer why women respondents fear more than men to declare their sexual orientation in their workplaces: it is a field in which gender disparity is still strong (Biasi and Fiorucci, 2018; Toffanin, 2018). The different treatment reserved for men and women makes difficult to come out in the workplaces and invisibility often becomes an obligatory choice.

\section{Discussion}

The scientific literature on the subject has repeatedly stressed that sexual minorities are victims of social stigma, which translates into harassment, threats and intimidations (see, e.g. Fisher et al., 2008; Herek and McLemore, 2013; Montgomery and Stewart, 2012). It is important to underline that, in this scenario, bisexual people represent a peculiar object of study, because they are double victims (see, e.g. Brewster et al., 2013, Dyar et al., 2014; Katz-Wise et al., 2017). The movement of bisexual people, in the Anglo-Saxon world, talks about "double discrimination" to refer to the common experience of many bisexual people feeling prejudiced and discriminated by both the heterosexual majority and the homosexual minority. Italian respondents indicated that they are experiencing this specific discomfort too and are reported to languish in the ambiguity of orientation, therefore leaving them immature and unable to develop a serious relationship. Another emerged belief is that bisexuality is a form of confusion or transgression, but research data dispel these prejudices, showing the daily lives of people well aware of their sexual orientation. Similar prejudices based on sexual differentiation have also affected other minorities over time. Studies - now obsolete considered women sentimentally immature as they manifest feelings and emotions more intensely than men. On the same line of thought there was the Freudian conception of homosexuality as the "arrest of development" (Freud, 1905). If over time these beliefs have been overcome for women and homosexual people, our research shows that in Italy this prejudice is still influencing bisexual people. They are victims of the belief that they are immature since they do not position themselves either as fully heterosexual or as fully homosexual.

Social pressure and misunderstanding by others sometimes make difficult for bisexual people to show themselves openly for what they are. From a sociological point of view, it can be argued that one of the tools with which bisexual people fight against the stigma related to bisexuality is carefully control the information they provide about themselves, evaluating the contexts in which they can free themselves and the time when they must expose themselves in line with the expectations of the heteronormative society. In some cases, they act for a compromise between the needs of the society and their desires (Guittar, 2013).

The survey also highlights that the contemporary Italian legislative system fails to protect bisexual people, but some virtuous cities offer spaces in which sexual minorities can locally enjoy public policy arrangements and services. The Italian government should work to ensure that full citizenship rights are guaranteed by all citizens. In particular, for bisexual citizens, a number of specific actions would be desirable to be carried out: first of all, a law against biphobia to punish discrimination based on sexual orientation would be needed. Physical and verbal violence constitutes a violation of the principle of equality and harms the human rights of bisexual people, who too often are forced to live in invisibility for fear. Secondly, civic educational interventions on bisexuality should find application among the 
whole population. In Italy, there is still no culture able to understand that differences between people must be considered important resources for a social and collective growth. In this scenario, a central role should be played by socialisation agents, such as schools and universities, which must explain to people not only the negative consequences of discriminations but also the value of the social inclusion. At the same time, a conceptualisation of sexual identity within diversity management policies in organisations that take into account the linkages between individual and organisational identity would be necessary. Many countries of the world are already experimenting with diversity inclusion policies that consider the sexual orientations of people as personality traits to be enhanced within the organisational strategies (see, e.g. Bizjak, 2019; Palo and Jha, 2020). Furthermore, some specific services should also be provided for bisexual people against the common obsolete proposal that bisexual people would fit into a combination of heterosexual and lesbian/gay services, which represents a further step towards a creation of a truly inclusive society that respects sexual diversities.

\section{Conclusions and implications}

The present study carries academic value and realistic importance for two main reasons. First, it enriches the international debate on bisexuality. Nowadays bisexuality remains under-researched in social sciences and overall in sociology. Under this critical point of view, putting bisexuality at the centre of the sociological attention appears important to provide serious and scientifically valid data and information useful both to develop the knowledge on this identity category and to contain forms of discrimination and prejudice. Second, Italian politics still struggles to fully recognise the citizenship rights of all sexual minorities. However, the constant pressing action carried on by the homosexual movement during the last decades has contributed to change, in part, the situation. The Italian claim of LGBT rights is characterised by a paradox: LGBT social movement is not unitary, but factions and different views are present internally (Corbisiero and Monaco, 2020). This situation has negatively impacted on the achievement of democratic goals, since the lack of a structured, decisive and compact bisexual Italian movement made this specific community unheard. According to Rinaldi (2012), in Italy, there is a regularising and normalising vision of the social reality. Consequently, Italy does not take charge of the protection of the rights of people who perceive themselves as moving between sexual identities and who do not recognise themselves within a binary sexual reality. Hence, this work is useful to deepen the "invisible B" phenomenon of the LGBT acronym in a systematic way. It introduces a specific discussion on this issue in Italy, showing that speaking about sexual orientations in general is not enough, but it is necessary to focus attention on individual sexual identities. In fact, the study has highlighted some specific needs of the Italian bisexual population that have not clearly emerged in the context of wider research on the Italian LGBT community.

A systemic analysis of bisexual people's condition may allow Italian researchers to suggest the implementation of specific social policies. Indeed, calling attention to social discrimination may help promote political and social change in Italy, contributing to increased respect for freedom and for democracy in general, and fight against biphobia and stigmatisation, in particular.

\section{References}

Albury, K. (2015), "Identity-plus?: bi-curiousity, hetero-flexibility and the boundaries of 'straight' sexual practices and identities", Sexualities, Vol. 18 No. 5, pp. 649-664.

Arcigay (2011), Io Sono Lavoro, Arcigay Nazionale, Rome. 
IJSSP

$41,5 / 6$

684

Balsam, K.F. and Mohr, J.J. (2007), "Adaptation to sexual orientation stigma: a comparison of bisexual and lesbian/gay adults", Journal of Counseling Psychology, Vol. 54, pp. 306-319.

Barbagli, M. and Colombo, A. (2001), Omosessuali moderni. Gay e lesbiche in Italia, Il Mulino, Bologna.

Bauman, Z. (2011), Culture in a Liquid Modern World, Polity, London.

Baumle, A.K., Compton, D.R. and Poston, D.L. (2009), Same Sex Partners: The Demography of Sexual Orientation, SUNY Press, New York.

Biasi, V. and Fiorucci, M. (Eds) (2018), Forme Contemporanee del Disagio, Roma Tre-Press, Rome.

Bizjak, D. (2019), Diversity Management and Identity in Organisations: From Liminality to Inclusion, Cambridge Scholars Publishing, Cambridge.

Breveglieri, M. (2007), Sessualità, Liminalità e "Lavoro di Confine”: il Caso Dell'esperienza Bisessuale, University of Padova, Padova.

Brewster, M.E. and Moradi, B. (2010), "Perceived experiences of anti-bisexual prejudice: instrument development and evaluation", Journal of Counseling Psychology, Vol. 57, pp. 451-468, doi: 10. 1037/a0021116.

Brewster, M.E., Moradi, B., De Blaere, C. and Velez, B.L. (2013), "Navigating the borderlands: the roles of minority stressors, bicultural self-efficacy and cognitive flexibility in the mental health of bisexual individuals", Journal of Counseling Psychology, Vol. 60, pp. 543-456, doi: 10.1037/ a0033224.

Butler, J.. (1990), Gender Trouble: Feminism and the Subversion of Identity, Routledge, London.

Caldwell, K. (2010), "We exist: intersectional in/visibility in bisexuality and disability", Disability Studies Quarterly, Vol. 30 No. 3, pp. 1-17.

Castro, A. and Carnassale, D. (2019), "Loving more than one color: bisexuals of color in Italy between stigma and resilience", Journal of Bisexuality, Vol. 19 No. 2, pp. 198-228, doi: 10.1080/15299716. 2019.1617548.

Chun, K.Y.S. and Singh, A.A. (2010), “The bisexual youth of color intersecting identities development model: a contextual approach to understanding multiple marginalization experiences", Journal of Bisexuality, Vol. 10 No. 4, pp. 429-451.

Corbisiero, F. (2013), Comunità Omosessuali. Le Scienze Sociali Sulla Popolazione Lgbt, Franco Angeli, Milan.

Corbisiero, F. and Monaco, S. (2017), Città Arcobaleno. Una Mappa Della Vita Omosessuale in Italia, Donzelli, Rome.

Corbisiero, F. and Monaco, S. (2020), "The right to a rainbow city: the Italian homosexual social movements", Society Register, Vol. 4 No. 4, pp. 1-18, doi: 10.14746/sr.2020.4.4.03.

Crenshaw, K. (1989), "Demarginalizing the intersection of race and sex: a black feminist critique of antidiscrimination doctrine, feminist theory and antiracist politics", Legal Forum, Vol. 1989 No. 1, pp. 139-167.

Crooks, R.L. and Baur, K. (2016), Our Sexuality,Cengage Learning, Boston.

Daniels, J. and Gregory, K. (2016), Digital Sociologies, Policy Press, London.

Davies, S.G. (2018), "Bisexuality", in Callan, H. (Ed.), The International Encyclopedia of Anthropology, John Wiley and Sons, Hoboken, pp. 1-2.

Dettore, D. and Lambiase, E. (2011), La Fluidità Sessuale: la Variazione Dell'orientamento e Del Comportamento Sessuale, Alpes, Rome.

Diamond, L.M. (2008), "Female bisexuality from adolescence to adulthood: results from a 10-year longitudinal study", Developmental Psychology, Vol. 44 No. 1, pp. 5-14, doi: 10.1037/0012-1649.44. 1.5 .

Diamond, L.M. (2009), Sexual Fluidity: Understanding Women's Love and Desire, Harvard University Press, Harvard. 
Dolata, U. and Schrape, J.F. (2018), Collectivity and Power on the Internet. A Sociological Perspective, Springer, Berlin.

Dyar, C., Feinstein, B.A. and Bonita, L. (2014), "Dimensions of sexual identity and minority stress among bisexual women: the role of partner gender", Psychology of Sexual Orientation and Gender Diversity, Vol. 1, pp. 441-451, doi: 10.1037/sgd0000063.

D’Augelli, A. (2002), "Mental health problems among lesbian, gay and bisexual youths ages 14 to 21", Clinical Child Psychology and Psychiatry, Vol. 7 No. 3, pp. 433-456, doi: 10.1177/ 1359104502007003039 .

D'Lane, R., Compton, D., Farris, N. and Yu-Ting, C. (2015), "Patterns of bisexuality in America", Journal of Bisexuality, Vol. 14 No. 4, pp. 481-497, doi: 10.1080/15299716.2015.1048919.

Edwards, A.. (1957), The Social Desirability Variable in Personality Assessment and Research. The Dryden Press, New York.

Eisner, S. (2013), Bi: Notes for a Bisexual Revolution, Seal Press, New York.

Elia, J.P. (2010), "Bisexuality and school culture: school as a prime site for biintervention", Journal of Bisexuality, Vol. 10 No. 4, pp. 452-471.

Eliason, M. and Elia, J.P. (2011), "Reflections about bisexuality and the journal of bisexuality", Journal of Bisexuality, Vol. 11 No. 4, pp. 412-419.

Fisher, E.S., Komosa-Hawkins, K., Saldaña, E., Thomas, G.M., Hsiao, C., Rauld, M. and Miller, D. (2008), "Promoting school success for lesbian, gay, bisexual, transgendered and questioning students: primary, secondary and tertiary prevention and intervention strategies", The California School Psychologist, Vol. 13, pp. 79-91, doi: 10.1007/BF03340944.

Feinstein, B.A. and Dyar, C. (2017), "Bisexuality, minority stress and health", Current Sexual Health Reports, Vol. 9, pp. 42-49, doi: 10.1007/s11930-017-0096-3.

Flanders, C.E. (2017), "Under the bisexual umbrella: diversity of identity and experience", Journal of Bisexuality, Vol. 17 No. 1, pp. 1-6, doi: 10.1080/15299716.2017.1297145.

FRA (2020), A Long Way to Go for LGBTI Equality, European Union Agency for Fundamental Rights, Bruxelles.

Freud, S. (1905), Drei Abhandlungen zur Sexualtheorie, Springer, Berlin.

Friedman, M.R., Dodge, B., Schick, V., Herbenick, D., Hubach, R., Bowling, J., Goncalves, G., Krier, S. and Reece, M. (2014), "From bias to bisexual health disparities: attitudes toward bisexual men and women in the United States", LGBT Health, Vol. 1 No. 4, pp. 309-318.

Goffman, E. (1963), Stigma: Notes on the Management of Spoiled Identity, Touchstone Press, New York

Guittar, N.A. (2013), "The queer apologetic: explaining the use of bisexuality as a transitional identity", Journal of Bisexuality, Vol. 13 No. 2, pp. 166-190, doi: 10.1080/15299716.2013. 781975 .

Gusmano, B. (2018), "Coming out through an intersectional perspective: narratives of bisexuality and polyamory in Italy", Journal of Bisexuality, Vol. 18 No. 1, pp. 15-34, doi: 10.1080/15299716.2017. 1416510.

Herek, G.M. (2002), "Heterosexuals' attitudes toward bisexual men and women in the United States", Journal of Sex Research, Vol. 39 No. 4, pp. 264-274.

Herek, G.M. and McLemore, K.A. (2013), "Sexual prejudice", Annual Review of Psychology, Vol. 64 No. 1, pp. 309-333, doi: 10.1146/annurev-psych-113011-143826.

Hine, C. (2005), Virtual Methods: Issues in Social Research on the Internet, Berg Publishers, Oxford. Huneke, S. (2019), Queering the Vote, Review of Books, Los Angeles.

Hunt, M.O., Braboy Jackson, P., Kye, S.H., Powell, B. and Carr Steelman, L. (2014), "Still color-blind? The treatment of race, ethnicity, intersectionality and sexuality in sociological social psychology", Advances in Group Processes, Vol. 30, pp. 21-45.
Being bisexual in contemporary Italy 
IJSSP

$41,5 / 6$

686

ILGA (2019), Annual Review 2019, International Lesbian, Gay, Bisexual, Trans and Intersex Association, Bruxelles.

Israel, T. and Mohr, J.J. (2004), "Attitudes toward bisexual women and men”, Journal of Bisexuality, Vol. 4 No. 1, pp. 117-135, doi: 10.1300/J159v04n01_09.

ISTAT (2015), La Popolazione Omosessuale Nella Società Italiana, ISTAT, Rome.

Jagose, A. (1996), Queer Theory. An Introduction, New York University Press, New York.

James, S.E., Herman, J.L., Rankin., S., Keisling, M., Mottet, L. and Anafi, M. (2016), The Report of the 2015 U.S. Transgender Survey, National Center for Transgender Equality, New York.

Katz-Wise, S.L., Mereish, E.H. and Woulfe, J. (2017), "Associations of bisexual-specific minority stress and health among cisgender and transgender adults with bisexual orientation", The Journal of Sex Research, Vol. 54, pp. 899-910, doi: 10.1080/00224499.2016.1236181.

King, A.R. (2013), "Mixed messages: how primary agents of socialization influence adolescent females who identify as multiracial-bisexual", Journal of LGBT Youth, Vol. 10 No. 4, pp. 308-327.

Klawitter, M. (2014), "Meta-analysis of the effects of sexual orientation on earnings", Industrial and Labor Relations Review, Vol. 54, No. 1, pp. 4-32.

Krumpal, I. (2013), "Determinants of social desirability bias in sensitive surveys: a literature review", Quality and Quantity, Vol. 47 No. 4, pp. 2025-2047, doi: 10.1093/poq/nfr036.

Liang, A.C. (1997), "The creation of coherence in coming-out stories", in Liviax, A. and Hall, K. (Eds), Queerly Phrased: Language, Gender and Sexuality, Oxford University Press, Oxford, pp. 287-309.

Matthews, J.D. and Cramer, E.P. (2008), "Using technology to enhance qualitative research with hidden population”, Qualitative Report, Vol. 13 No. 2, pp. 301-315.

McPhail, B.A. (2004), "Questioning gender and sexuality binaries: what queer theorists, transgendered individuals and sex researchers can teach social work", Journal of Gay and Lesbian Social Services, Vol. 17 No. 1, pp. 3-21.

Mize, T.D. (2015), "What social psychology can contribute to the study of sex, gender and sexual orientation", Sociology Compass, Vol. 9 No. 12, pp. 1066-1081.

Mize, T.D. (2016), "Sexual orientation in the labor market", American Sociological Review, Vol. 81 No. 6, pp. $1132-1160$.

Monaco, S. (2019), "Mixed methods e e-research: frontiere possibili per lo studio delle hiddenpopulation”, Sociologia Italiana, Vol. 14, pp. 97-108, doi: 10.1485/AIS_2019/14_3443558.

Montgomery, S.A. and Steward, A.J. (2012), "Privileged allies in lesbian and gay rights activism: gender, generation and resistance to heteronormativity", Journal of Social Issues, Vol. 8 No. 1, pp. 162-177.

Pallotta-Chiarolli, M. (2014), "Erasure, exclusion by inclusion and the absence of intersectionality: introducing bisexuality in education”, Journal of Bisexuality, Vol. 14 No. 1, pp. 7-17, doi: 10.1080/ 15299716.2014.872454.

Palo, S. and Jha, K.K. (2020), Queer at Work, Palgrave Macmillan, Singapore.

Peplau, L.A. and Garnets, L.D. (2000), “A new paradigm for understanding women's sexuality and sexual orientation”, Journal of Social Issues, Vol. 56 No. 2, pp. 329-350, doi: 10.1111/00224537.00169.

Petrocchi, N., Pistella, J., Salvati, N., Carone, N., Laghi, F. and Baiocco, R. (2020), "I embrace my LGB identity: self-reassurance, social safeness and the distinctive relevance of authenticity to wellbeing in Italian lesbians, gay men and bisexual people", Sexuality Research and Social Policy, Vol. 17, pp. 75-86, doi: 10.1007/s13178-018-0373-6.

Pietrantoni, L., Lelleri, R. and Graglia, M. (2005), Pazienti imprevisti: pratica medica e orientamento sessuale, Arcigay Nazionale, Bologna. 
Pistella, J., Salvati, M., Ioverno, S., Laghi, F. and Baiocco, R. (2016), "Coming-out to family members and internalized sexual stigma in bisexual, lesbian and gay people", Journal of Child and Family Studies, Vol. 25, pp. 3694-3701, doi: 10.1007/s10826-016-0528-0.

Rasmussen, M.L. (2004), “The problem of coming out”, Theory Into Practice, Vol. 43, pp. 144-150, doi: 10.1207/s15430421tip4302_8.

Rinaldi, C. (Ed.). (2012), Alterazioni: Introduzione Alle Sociologie Delle Omosessualità, Mimesis, Milano.

Rodriguez, E.M., Lytle, M.C. and Vaughan, M.D. (2013), "Exploring the intersectionality of bisexual, religious/spiritual and political identities from a feminist perspective", Journal of Bisexuality", Vol. 13 No. 3, pp. 285-309, doi: 10.1080/15299716.2013.813001.

Ron, P., Grant Smith, N., Mohr, J.J. and Ross, L.E. (2014), "Measuring dimensions of bisexual identity: initial development of the Bisexual Identity Inventory", Psychology of Sexual Orientation and Gender Diversity, Vol. 1, pp. 452-460, doi: 10.1037/t37065-000.

Ruspini, E. (2013), "Identità e sessualità Lgbt: quali spazi offre la ricerca sociale in Italia?”, in Corbisiero, F. (Ed.), Comunità Omosessuali. Le Scienze Sociali Sulla Popolazione Lgbt, Franco Angeli, Milan, pp. 165-180.

Rust, P.C.R. (Ed.). (2000), Bisexuality in the United States: A Social Science Reader, Columbia University Press, New York.

Savin-Williams, R.C., Joyner, K. and Rieger, G. (2012), "Prevalence and stability of self-reported sexual orientation identity during young adulthood", Archives of Sexual Behavior, Vol. 41, No. 1, pp. 1-8, doi: 10.1007/s10508-012-9913-y.

Scherrer, K.S., Kazyak, E. and Schmitz, R. (2015), "Getting 'Bi' in the family: bisexual people's disclosure experiences", Journal of Marriage and Family, Vol. 77 No. 3, pp. 680-696.

Scandurra, C., Pennasilico, A., Esposito, C., Mezza, F., Vitelli, R., Bochicchio, V., Maldonato, N. and Amodeo, A. (2020), "Minority stress and mental health in Italian bisexual people", Social Sciences, Vol. 9 No. 46, pp. 1-17, doi: 10.3390/socsci9040046.

Seidman, S. (2002), Beyond the Closet: The Transformation of Gay and Lesbian Life, Psychology Press, New York.

Snee, H., Hine, C., Morey, Y., Roberts, S. and Watson, H. (2016), Digital Methods for Social Science. An Interdisciplinary Guide to Research Innovation, Palgrave Macmillan, London.

Surratt, C.G. (2001), The Internet and Social Change, McFarland, New York.

Toffanin, T. (2018), "Donne al lavoro in Italia tra parità formale e disparità sostanziale", in Basso, P. and Chiaretti, G. (Eds.), Le Grandi Questioni Sociali Del Nostro Tempo, Università Ca' Foscari, Venezia.

Trappolin, L. and Gusmeroli, P. (2020), Raccontare l'omofobia in Italia: Genesi e Sviluppi di Una Parola Chiave, Rosnberg and Sellier, Turin.

Veaux, F. and Rickert, E. (2014), More Than Two: A Practical Guide to Ethical Polyamory, Thorntree Press, Portland.

Verrastro, V., Fontanesi, L., Petruccelli, I., Santamaria, F., Laghi, F., Ioverno, S. and Baiocco, R. (2016), "Binge drinking and internalised sexual stigma among Italian lesbian, gay and bisexual young adults", Nordic Studies on Alcohol and Drugs, Vol. 4, pp. 437-446, doi: 10.1515/nsad-2016-0035.

Weinberg, M.S., Williams, C.J. and Douglas, P.W. (1995), Dual Attraction: Understanding Bisexuality, Oxford University Press, Oxford.

Weiten, W., Dunn, D.S. and Yost, H.E. (2016), Psychology Applied to Modern Life: Adjustment in the 21st Century, Cengage Learning, Boston.

Worthen, M.G.F. (2013), “An argument for separate analyses of attitudes toward lesbian, gay, bisexual men, bisexual women, MtF and FtM transgender individuals", Sex Roles, Vol. 68 No. 11, pp. 703-723.

Yoshino, K. (2006), Covering: The Hidden Assault on Our Civil Rights, Random House Publishing Group, New York. 
IJSSP

$41,5 / 6$

\section{8}

Yost, M.R. and Genea, D.T. (2012), “Gender and binegativity: men's and women's attitudes toward male and female bisexuals", Archives of Sexual Behavior, Vol. 41 No. 3, pp. 691-702.

Zimmam, L. (2009), "The other kind of coming out: transgender people and the coming out narrative genre", Gender and Language, Vol. 3, No. 1, pp. 53-80, doi: 10.1558/genl.v3i1.53.

\section{About the author}

Salvatore Monaco is a postdoctoral researcher in Sociology at the Faculty of Education, Free University of Bozen (Italy), where he is adjunct professor of "Genders, Identities and Territories". He achieved the $\mathrm{PhD}$ degree in "Social Sciences and Statistics" at the Department of Social Sciences, University of Naples Federico II. He has been a researcher of Osservatorio LGBT and OUT (Osservatorio Universitario sul Turismo) of the University of Naples Federico II for several years. His research interests include tourism, technologies and territories with particular focus on identities, genders, sexual orientations and generations. Salvatore Monaco is the corresponding author and can be contacted at: salvatore.monaco@ unibz.it

For instructions on how to order reprints of this article, please visit our website: 